\title{
O ENVELHECIMENTO DA POPULAÇÃO MUNDIAL. UM DESAFIO NOVO
}

\author{
Alexandre Kalache * \\ Renato P. Veras ** \\ Luiz Roberto Ramos ***
}

\begin{abstract}
KALACHE, A. et al. O envelhecimento da população mundial. Um desafio novo. Rev. Saúde públ., S. Paulo, 21:200-10, 1987.

RESUMO: O envelhecimento populacional é hoje um fenômeno universal, característico tanto dos países desenvolvidos como, de modo crescente, do Terceiro Mundo. São apresentados dados que ilustram a verdadeira revolução demográfica desde o início do século e estimativas até o ano 2025. Os fatores responsáveis pelo envelhecimento são discutidos, com especial referência ao declínio tanto das taxas de fecundidade como das de mortalidade. Em conjunto, tais declínios levam a um menor ingresso de jovens em populações que passam a viver períodos mais longos. Esse processo gradativo é conhecido como "transição epidemiológica" e seus vários estágios são abordados. As repercussões para a sociedade, de populações progressivamente mais idosas são consideráveis, particularmente no que diz respeito à saúde. Os padrões de mortalidade e morbidade são discutidos e o conceito de autonomia, como uma forma de quantificar qualidade de vida, é introduzido. É proposta redefinição do próprio conceito de envelhecimento, refletindo a realidade médico-social do Terceiro Mundo. São formuladas questões sobre a interação envelhecimento-mudanças sociais em curso nos países subdesenvolvidos, cujas respostas podem ser grandemente facilitadas pelo uso do método epidemiológico.
\end{abstract}

UNITERMOS: Envelhecimento da população, tendências. Taxas de mortalidade, tendências. Taxas de fecundidade, tendências. Expectativa de vida. Qualidade de vida. Mudanças sociais.

\section{INTRODUÇÃO}

Desde a década de 50, a maioria dos idosos vive em países do Terceiro Mundo, fato ainda não apreciado por muitos que continuam associando velhice com os países mais desenvolvidos da Europa ou da América do Norte. Na verdade, já em 1960, mais da metade das pessoas com mais de 65 anos vivia nos países do Terceiro Mundo (United Nations ${ }^{17}$, 1985). Projeções demográficas indicam que de 1980 até o final do século cerca de três quartos do aumento da população idosa ocorrerão em tais países (Hoover e Siegel ${ }^{10}$ - Tabela 1), fazendo com que este seja o grupo etário que mais crescerá na maioria dos países menos desenvolvidos. $\mathrm{Na}$ América Latina, entre 1980 e o ano 2000 deverá ocorrer um aumento de $120 \%$ da população total (de 363,7 para 803,6 milhões), enquanto que o aumento da população acima de 60 anos será de $236 \%$ (de 23,3 para 78,2 milhões), ou seja, duas vezes maior que o percentual de aumento da população como um todo. A longo prazo, as perspectivas são ainda mais impressionantes. A Tabela 2 mostra os aumentos das populações idosas em países que terão 16 milhões ou mais de pessoas acima de 60 anos no ano 2025, comparadas com as populações da mesma faixa etária em $1950\left(\mathrm{WHO}^{23}, 24\right)$. Entre os 11 países com as maiores populações de idosos daqui a quarenta anos, 8 situam-se na categoria de países em desenvolvimento de acordo com os critérios atuais. Haverá, portanto, uma substituição: as grandes populações idosas dos países eưropeus cedendo lugar a países caracteristicamente jovens como a Nigéria, Brasil ou Paquistão. Em termos práticos, o aumento é sem precedentes. Por exemplo, no Brasil, o aumento da população idosa será da ordem de 15 vezes, entre 1950 e 2025 , enquanto o da população como um todo será de não mais que cinco vezes no mesmo período. Tal aumento colocará o Brasil, no ano 2025, com a sexta população de idosos do mundo em termos absolutos (Kalache e Gray ${ }^{13}$, 1985).

* Unit for the Epidemiology of Ageing. London School of Hygiene and Tropical Medicine - Keppel Street, London, WCIE 7HT. - England.

** Instituto de Medicina Social da Universidade do Estado do Rio de Janeiro (IMS-UERJ) - Rua São Francisco Xavier, 524 - 20550 - Rio de Janeiro, RJ - Brasil.

*** Departamento de Medicina Preventiva da Escola Paulista de Medicina - Rua Botucatu, 740 - 04023 - São Paulo, SP - Brasil. 
TABELA 1

População total de pessoas idosas: 1960-2020 (em milhões; projeções são variantes médias)

\begin{tabular}{|c|c|c|c|c|c|c|c|}
\hline \multirow[b]{2}{*}{ Regiōes } & & \multicolumn{3}{|c|}{1960} & \multicolumn{3}{|c|}{1980} \\
\hline & & $\begin{array}{c}\text { População } \\
\text { total }\end{array}$ & $\begin{array}{l}\text { Acima de } \\
65 \text { anos }\end{array}$ & $\begin{array}{c}\text { Acima de } \\
80 \text { anos }\end{array}$ & $\begin{array}{c}\text { População } \\
\text { total }\end{array}$ & $\begin{array}{c}\text { Acima de } \\
65 \text { anos }\end{array}$ & $\begin{array}{c}\text { Acima de } \\
80 \text { anos }\end{array}$ \\
\hline Mundo & & $3.037,0$ & 165,3 & 19,9 & $4.432,1$ & 259,5 & 35,3 \\
\hline $\begin{array}{l}\text { Regiões mais } \\
\text { desenvolvidas }\end{array}$ & (a) & 944,9 & 80,3 & 11,7 & $1.131,3$ & 127,8 & 20,9 \\
\hline $\begin{array}{l}\text { Regiões menos } \\
\text { desenvolvidas }\end{array}$ & (b) & $2.092,3$ & 85,0 & 8,1 & $3.300,8$ & 131,7 & 14,4 \\
\hline
\end{tabular}

\begin{tabular}{|c|c|c|c|c|c|c|c|}
\hline \multirow[b]{2}{*}{ Regiões } & & \multicolumn{3}{|c|}{2000} & \multicolumn{3}{|c|}{2020} \\
\hline & & $\begin{array}{c}\text { População } \\
\text { total }\end{array}$ & $\begin{array}{c}\text { Acima de } \\
65 \text { anos }\end{array}$ & $\begin{array}{l}\text { Acima de } \\
80 \text { anos }\end{array}$ & $\begin{array}{l}\text { População } \\
\text { total }\end{array}$ & $\begin{array}{l}\text { Acima de } \\
65 \text { anos }\end{array}$ & $\begin{array}{c}\text { Acima de } \\
80 \text { anos }\end{array}$ \\
\hline Mundo & & $6.118,9$ & 402,9 & 59,6 & $7.813,0$ & 649,2 & 101,6 \\
\hline $\begin{array}{l}\text { Regiões mais } \\
\text { desenvolvidas }\end{array}$ & (a) & $1.272,2$ & 166,0 & 30,2 & $1.360,2$ & 212,4 & 43,4 \\
\hline $\begin{array}{l}\text { Regiões menos } \\
\text { desenvolvidas }\end{array}$ & (b) & $4.846,7$ & 236,9 & 29,4 & $6.452,8$ & 436,9 & 58,2 \\
\hline
\end{tabular}

(a) Regiões mais desenvolvidas: América do Norte, Europa, Japão, Austrália, Nova Zelândia e União Soviética.

(b) Regiōes menos desenvolvidas: África, América Latina, Ásia (exceto Japão), Oceania (exceto Austrália e Nova

Fonte: Hoover e Siegel ${ }^{10}, 1986$.

Zelândia).

O ENVELHECIMENTO POPULACIONAL ANTES E DEPOIS DOS PROGRESSOS MÉDICO-TECNOLÓGICOS

O envelhecimento da população mundial é um fenômeno novo ao qual mesmo os países mais ricos e poderosos ainda estão tentando se adaptar. O que era no passado privilégio de alguns poucos passou a ser uma experiência de um número crescente de pessoas em todo o mundo. Envelhecer no final deste século já não é proeza reservada a uma pequena parcela da população. No entanto, no que se refere ao envelhecimento populacional, os países desenvolvidos diferem substancialmente dos subdesenvolvidos, já que os mecanismos que levam a tal envelhecimento são distintos.

$\mathrm{Na}$ Europa, por exemplo, o aumento na expectativa de vida ao nascimento já havia sido substancial à época em que ocorreram importantes conquistas do conhecimento médico, em meados deste séculos. Este fato pode ser ilustrado pelo clássico exemplo da redução da mortalidade por tuberculose. Na Inglaterra, em 1855, 13 de cada 100 mortes eram atribuídas a tuberculose (Aldestein $\left.{ }^{1}, 1977\right)$. Nos Estados Unidos, no início deste século, a taxa de mortalidade por essa doença era de 194 mortes para cada 100.000 indivíduos em um ano.

TABELA 2

Mudanças na população de países que terão mais de 16 milhões de pessoas com 60 anos ou mais no ano 2025

\begin{tabular}{|c|c|c|c|c|c|c|}
\hline \multirow{2}{*}{ Países } & \multicolumn{6}{|c|}{ População (000 000) } \\
\hline & Class. em 1950 & 1950 & 1975 & 2000 & 2025 & Class.em 2025 \\
\hline China & $1 \%$ & 42 & 73 & 134 & 284 & $1 \stackrel{\circ}{\circ}$ \\
\hline Índia & 2 ? & 32 & 29 & 65 & 146 & $2 ?$ \\
\hline URSS & $4 \stackrel{\circ}{\circ}$ & 16 & 34 & 54 & 71 & $3 \stackrel{\circ}{\circ}$ \\
\hline EUA & 3 ? & 18 & 31 & 40 & 67 & $4^{\circ}$ \\
\hline Japão & $8 \stackrel{\circ}{\circ}$ & 6 & 13 & 26 & 33 & $5:$ \\
\hline Brasil & $16^{\circ}$ & 2 & 6 & 14 & 32 & $6{ }^{\circ}$ \\
\hline Indonésia & $10^{\circ}$ & 4 & 7 & 15 & 31 & $7{ }^{\circ}$ \\
\hline Paquistão & 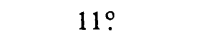 & 3 & 3 & 7 & 18 & $8{ }^{\circ}$ \\
\hline México & $25^{\circ}$ & 1 & 3 & 6 & 17 & $99^{\circ}$ \\
\hline Bangladesh & $14^{\circ}$ & 2 & 3 & 6 & 17 & $10^{\circ}$ \\
\hline Nigéria & $27 ?$ & 1 & 2 & 6 & 16 & $11^{\circ}$ \\
\hline
\end{tabular}

Fonte: World Health Statistics Annuals ${ }^{23},{ }^{24} 1979,1982$. 


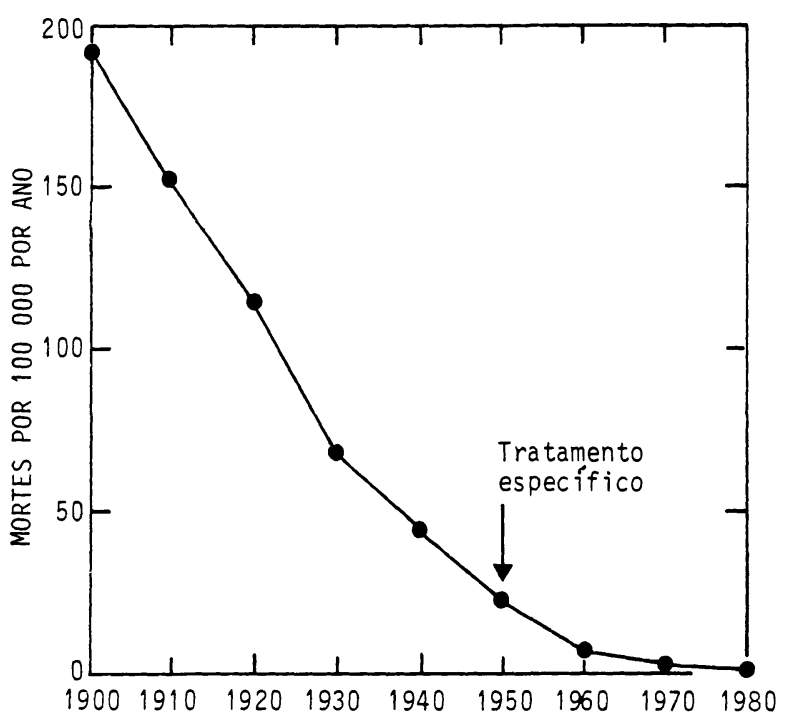

Fig. 1 - Declínio das taxas de mortalidade por tuberculose respiratória nos Estados Unidos de 1900 a 1980. Fonte: Fries e Crapo ${ }^{6}(1981)$

Em 1925, a taxa estava reduzida ao meio, e a partir de 1940, a cada década a taxa foi novamente cortada pela metade (Fries e Crapo $\left.{ }^{6}, 1981\right)$. Comparando-se os dias atuais com os de 1900, nos Estados Unidos, constatase uma redução de $99 \%$ (Figura 1). A principal razão associada a esse drástico declínio é a elevação do nível de vida da população, traduzido pela urbanização adequada das cidades, melhoria nutricional, elevação dos níveis de higiene pessoal, melhores condições sanitárias em geral e, particularmente, condições ambientais no trabalho e nas residências muito melhores que anteriormente. Todos esses fatores já estavam presentes quando, no final da década de 40 e início dos anos 50, foram introduzidos os exames radiográficos, a vacina $\mathrm{BCG}$ e toda uma gama de drogas potentes que tiveram importante papel catalisador na redução contínua da incidência e prevalência da tuberculose; no entanto, o processo já estava há muito desencadeado.

Em países do Terceiro Mundo, por outro lado, aumento substancial na expectativa de vida ao nascimento pode ser observado a partir de 1960. Desde então até o ano 2020, as estimativas são de um crescimento bastante acentuado; a expectativa média de vida ao nascimento no Terceiro Mundo nesses sessenta anos terá aumentado mais de 23 anos, atingindo 68,9 anos em 2020 (Siegel e Hoover ${ }^{20}$ - Tabela 3 ).

No mesmo período, no entanto, o aumento na expectativa de vida para pessoas nascidas em países desenvolvidos será comparativamente muito menor, passando de 69,8 anos em 1960 para 77,2 em 202020 (Tabela 4). $\mathrm{Na}$ verdade, essa estabilização na taxa de crescimento da expectativa de vida nos países desenvolvidos é o que inevitavelmente se poderia esperar, tendo em vista o limite biológico de vida da espécie humana, ultrapassado somente por uma pequena parcela da população (Sacher ${ }^{19}$, 1981). Isso é uma verdade para todos os seres vivos; assim, se é excepcional para um cachorro viver mais que quinze anos, um rato, três ou um elefante setenta, para a espécie humana esse "relógio biológico" se situa em torno dos 85 anos. Cabe ressaltar que, de acordo com vários registros desde os primórdios da História, tal limite biológico de vida para a espécie humana não parece ter se alterado em milênios. Tampouco há evidência, através de comparações internacionais, de que ele seja diferente numa região do mundo comparada com outra (Fries e Crapo ${ }^{6}, 1981$ ). Portanto, quanto maior o número de pessoas que atinge idades próximas ao limite biológico de vida para a espécie humana, menor é a chance de que a expectativa de vida ao nascimento possa crescer de modo significativo.

Considerando-se o exemplo do Brasil, no início do século, a expectativa de vida ao nascimento era de 33,7 anos, tendo atingido 43,2 em 1950. No decorrer da década imediatamente posterior a expectativa de vida havia aumentado em quase 8 anos (55,9 em 1960). Na década seguinte a expectativa de vida ao nascimento passou a 57,1 e em 1980 ela atingiu 63,5 anos (Fundação IBGE $\left.^{2}, 1982\right)$; desde então até o ano 2000 ela deverá experimentar um aumento de cinco anos, quando um brasileiro ao nascer esperará viver por 68,5 anos. Importantes que sejam estes aumentos, espera-se que aos poucos o diferencial entre a expectativa de vida de brasileiros ricos e pobres possa ser diminuída. Em termos atuais essa diferença é elevada: cerca de 15 anos, refletindo a profunda divisão social e econômica que sempre existiu no país e que foi acentuada nas décadas mais recentes.

TABELA 3

Expectativa de vida ao nascimento em alguns países ou regiões menos desenvolvidas em $1960 / 5,1980 / 5,2000 / 5$ e $2020 / 5$ (em anos)

\begin{tabular}{lcccc}
\hline \multicolumn{1}{c}{ Países } & $1960 / 5$ & $1980 / 5$ & $2000 / 5$ & $2020 / 5$ \\
\hline Todos os Países & 45,6 & 56,6 & 63,2 & 68,9 \\
subdesenvolvidos & 45,1 & 53,6 & 61,8 & 68,7 \\
Ásia do Sul & 56,5 & 64,1 & 69,4 & 72,2 \\
América Latina & 55,9 & 63,4 & 68,6 & 72,1 \\
Brasil & 41,6 & 49,7 & 57,6 & 64,9 \\
África & 46,5 & 55,9 & 65,1 & 71,0 \\
África do Norte & & &
\end{tabular}

Fonte: Siegel e Hoover ${ }^{20}, 1982$ 
TABELA 4

Expectativa de vida ao nascimento em alguns países ou regiões desenvolvidas em 1960/5, 1980/5, 2000/5 e 2020/5 (em anos)

\begin{tabular}{lcccc}
\hline \multicolumn{1}{c}{ Países } & $1960 / 5$ & $1980 / 5$ & $2000 / 5$ & $2020 / 5$ \\
\hline $\begin{array}{l}\text { Todos os países } \\
\text { subdesenvolvidos }\end{array}$ & 69,8 & 73,0 & 75,9 & 77,2 \\
Japão & 68,9 & 76,6 & 77,7 & 78,1 \\
Austrália e & 70,9 & 74,2 & 76,5 & 77,5 \\
$\begin{array}{l}\text { Nova Zelândia } \\
\text { América do }\end{array}$ & 70,1 & 74,1 & 76,5 & 77,5 \\
Norte & 70,8 & 74,1 & 76,4 & 77,5 \\
Europa & 78,8 & 71,7 & 75,2 & 76,8 \\
Ocidental & 70,0 & 70,9 & 74,7 & 76,7 \\
Europa & & & \\
Oriental & & & & \\
\hline
\end{tabular}

Fonte: Siegel e Hoover ${ }^{20}, 1982$

TABELA 5

Expectativa de vida ao nascimento para homens e mulheres em alguns países e regiões desenvolvidas nos anos 1960/5, 1980/5, 2000/5 e 2020/5 (em anos)

\begin{tabular}{|c|c|c|c|c|c|c|c|c|}
\hline \multirow{2}{*}{ Países } & \multicolumn{2}{|c|}{$1960 / 5$} & \multicolumn{2}{|c|}{$1980 / 5$} & \multicolumn{2}{|c|}{$2000 / 5$} & \multicolumn{2}{|c|}{$2020 / 5$} \\
\hline & $\mathrm{H}$ & $\mathrm{M}$ & $\mathrm{H}$ & $\mathrm{M}$ & $\mathrm{H}$ & $\mathrm{M}$ & $\mathrm{H}$ & $\mathrm{M}$ \\
\hline $\begin{array}{l}\text { Todos os países } \\
\text { desenvolvidos }\end{array}$ & 66,6 & 72,8 & 69,4 & 76,9 & 72,3 & 79,7 & 73,8 & 80,8 \\
\hline Japão & 66,5 & 71,6 & 74,0 & 79,4 & 75,0 & 80,6 & 75,0 & 81,4 \\
\hline $\begin{array}{l}\text { Austrália e } \\
\text { Nova Zelândia }\end{array}$ & 67,9 & 74,1 & 70,9 & 77,7 & 73,0 & 80,2 & 74,2 & 81,0 \\
\hline $\begin{array}{l}\text { América do } \\
\text { Norte }\end{array}$ & 66,9 & 73,5 & 70,4 & 78,1 & 72,8 & 80,3 & 74,0 & 81,1 \\
\hline $\begin{array}{l}\text { Europa } \\
\text { Ocidental }\end{array}$ & 67,8 & 73,8 & 70,5 & 77,9 & 72,9 & 80,2 & 74,1 & 81,1 \\
\hline $\begin{array}{l}\text { Europa } \\
\text { Oriental }\end{array}$ & 66,5 & 71,3 & 68,5 & 75,1 & 71,8 & 78,8 & 73,4 & 80,5 \\
\hline URSS & 65,5 & 73,2 & 66,5 & 75,4 & 70,7 & 78,9 & 73,0 & 80,5 \\
\hline
\end{tabular}

Fonte: United Nations ${ }^{17}, 1984$

A expectativa de vida da mulher é maior que a dos homens, sobretudo nos países desenvolvidos - uma diferença de 7,5 anos em $1980^{17}$ (Tabela 5). As razões para tanto e suas implicações sociais são discutidas em outro artigo (Veras e $\left.\mathrm{col}^{22}, 1987\right)$. Já nos países menos desenvolvidos, essa diferença é bem menor - 2,2 anos para o conjunto de tais países ${ }^{17}$ (Tabela 6) - ou mesmo invertida. Esse é o caso do Paquistão, por exemplo, onde a expectativa de vida da mulher em 1980 era de 50 anos comparada com 52 anos para o homem, refletindo desigualdades entre um sexo e outro em relação a fatores como acesso a cuidados médicos, alta mortalidade materna e mesmo diferenças quanto à disponibilidade de alimentos de acordo com o sexo das crianças. A diferença entre a expectativa de vida ao nascimento de acordo com o sexo nos países da América Latina e Caribe ocupa uma posição intermediária entre as observadas nos países desenvolvidos e nos demais países do Terceiro Mundo (Anzola-Perez ${ }^{3}$, 1985). Em 1975-80 a diferença era de 5,4 anos $(60,5$ para homens e 65,9 para mulheres); as projeções indicam que ela se manterá prati- camente inalterada nos próximos anos, em torno de 5,9 anos entre 1995-2000, quando as expectativas de vida deverão alcançar 64,5 e 70,4 respectivamente para o sexo masculino e feminino ${ }^{3}$.

Finalmente, é importante notar que embora as diferenças entre as atuais expectativas de vida ao nascimento sejam consideráveis quando se comparam países desenvolvidos com os do Terceiro Mundo, elas se tornam muito menores quando se comparam as expectativas de vida em idades mais avançadas (Siegel e Hoover ${ }^{20}, 1982$ - Figura 2). Por exemplo, na Grécia a expectativa de vida aos sessenta anos é uma das mais altas do continente europeu, apesar de o país figurar entre os mais pobres da região. No México, em 1970, a expectativa de vida para uma mulher ao atingir os 65 anos de idade era cerca de 3 anos mais elevada que nos Estados Unidos em 1970. Já aos 45 anos a expectativa de vida de uma mulher em São Paulo é mais elevada do que a expectativa de vida de uma mulher da mesma idade vivendo na Inglaterra (Ramos e col. $\left.{ }^{18}, 1987\right)$. Isso se de- 


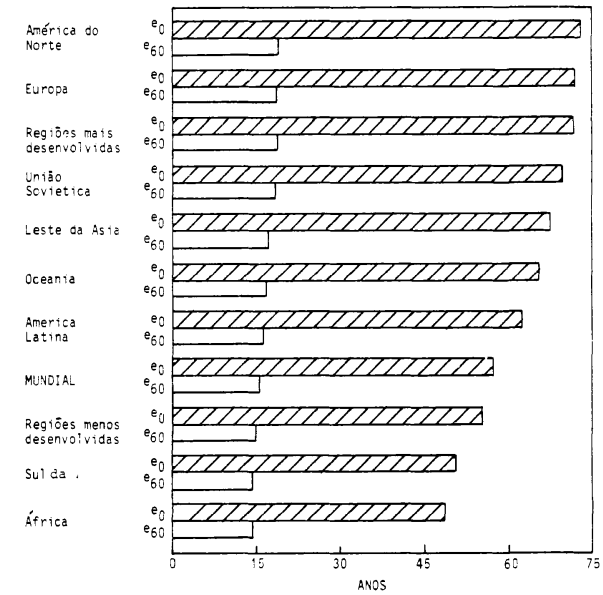

Fig.2 Expectativa de vida ao nascer e aos 60 anos, várias regiões do mundo de 1975/80

$\mathrm{e}_{0}=$ Expectativa de vida no nascimento

$\mathrm{e}_{60}=$ Expectativa de vida aos 60 anos

Fonte: $\mathrm{OMS}^{16}$, (1984)

ve a dois fatores concomitantes. Em primeiro lugar há que se levar em consideração o fato de que o estilo de vida, daqueles que sobreviveram até idades mais avançadas em países menos desenvolvidos, está associado a fatores de risco menos acentuados para determinadas doenças. Por exemplo, o consumo generalizado do tabaco ocorreu mais recentemente em tais países, e somente nos últimos anos a incidência de doenças como câncer de pulmão tem mostrado sensíveis aumentos. Além do fumo, a hiperalimentação, a relativa falta de atividade física e a exposição constante a fatores de estresse são todos componentes do estilo de vida do mundo moderno mais desenvolvido e que terminam por elevar a incidência de doenças cardiovasculares, de certos tipos de câncer e de certos tipos de distúrbios como o diabetes. Por outro lado, as taxa de mortalidade por doenças infecciosas e parasitárias são baixas na idade adulta, mesmo nos países subdesenvolvidos. Uma vez atingida a idade adulta, as causas de morte variam pouco, e a maioria das pessoas termina morrendo de doenças crônico-degenerativas, quer vivam em países desenvolvidos ou não.

\section{O PROCESSO DE TRANSIÇÃO EPIDEMIOLÓGICA OU DEMOGRÁFICA*}

Os significativos ganhos na expectativa de vida das populações européias estão ligados historicamente a uma melhor qualidade de vida experimentada pela maioria da população; conquistas médico-tecnológicas de relevância foram, quase todas, subseqüentes. Em recente artigo é discutido, de modo bastante abrangente, um paralelo entre a Alemanha Ocidental e o Brasil (Imhof ${ }^{11}$, 1985). No entanto, ainda que muitos milhões de pessoas continuem vivendo em graus absolutos de pobreza por todo o mundo menos desenvolvido, as conquistas tecnológicas da medicina moderna, ao longo dos últimos cinqüenta anos, conduziram a meios que tornam possível previnir ou curar muitas das doenças fatais do passado. $\mathrm{O}$ aumento atual na expectativa de vida conseqüente à redução da mortalidade verificada na maioria dos países subdesenvolvidos é, portanto, um fenômeno que se pode chamar artificial, já que está ocorrendo em função da disponibilidade de meios inexistentes até um passado muito próximo.

\section{A importância das taxas de fertilidade}

Em grande parte, o aumento atual do número de pessoas idosas em países menos desenvolvidos é decorrente do alto número de nascimentos durante as primeiras décadas deste século, associado a um progressivo decréscimo nas taxas de mortalidades. Da mesma forma, o envelhecimento da população de países europeus das últimas décadas se deve a taxas de natalidade relativamente altas no primeiro quarto do século associadas a taxas decrescentes de mortalidades em todos os grupos etários. Em seguida as taxas de natalidade decairam, fazendo com que a proporção de adultos progressivamente aumentasse. O processo é portanto dinâmico; para que uma população envelheça é necessário primeiro que nasçam muitas crianças, segundo que as mesmas sobrevivam até idades avançadas e que, simultaneamente, o número de nascimentos diminua. Com isso a entrada de

TABELA 6

Expectativa de vida ao nascer para homens e mulheres em alguns países e regiões subdesenvolvidas nos anos 1960/5, 1980/5, 2000/5 e 2020/5 (em anos)

\begin{tabular}{|c|c|c|c|c|c|c|c|c|}
\hline \multirow{2}{*}{ Países } & \multicolumn{2}{|c|}{$1960 / 5$} & \multicolumn{2}{|c|}{$1980 / 5$} & \multicolumn{2}{|c|}{$2000 / 5$} & \multicolumn{2}{|c|}{$2020 / 5$} \\
\hline & $\mathrm{H}$ & $\mathbf{M}$ & $\mathrm{H}$ & $\mathrm{M}$ & $\mathrm{H}$ & $\mathbf{M}$ & $\mathrm{H}$ & $\mathrm{M}$ \\
\hline $\begin{array}{l}\text { Todos os países } \\
\text { subdesenvolvidos }\end{array}$ & 44,9 & 46,5 & 55,5 & 57,7 & 61,9 & 64,6 & 67,2 & 70,7 \\
\hline China & 42,7 & 45,6 & 65,5 & 69,4 & 70,0 & 73,9 & 73,2 & 76,9 \\
\hline Ásia do Sul & 45,1 & 45,0 & 53,5 & 53,8 & 61,9 & 64,6 & 67,2 & 70,7 \\
\hline América Latina & 54,6 & 58,4 & 61,8 & 66,5 & 66,8 & 72,0 & 69,6 & 75,0 \\
\hline Brasil & 54,0 & 57,8 & 60,9 & 66,0 & 65,7 & 71,6 & 69,1 & 75,3 \\
\hline África & 40,3 & 43,0 & 48,2 & 51,3 & 55,9 & 59,4 & 63,0 & 66,8 \\
\hline África do Norte & 45,8 & 47,3 & 54,8 & 57,0 & 63,6 & 66,6 & 68,9 & 73,2 \\
\hline
\end{tabular}

Fonte: United Nations ${ }^{17}, 1984$

\footnotetext{
* O termo "transição epidemiológica" é usado em preferência ao de "transição demográfica", que denota as mudanças na estrutura etária responsável, em última análise, pelo processo aqui descrito.
} 
jovens na população decresce, e a proporção daqueles que sobreviveram até idades mais avançadas passa a crescer.

As taxas de fertilidade da maioria dos países estão em declínio ${ }^{17}$ (Tabela 7 - Fig. 3). No entanto, mesmo um rápido declínio nas mesmas, como por exemplo o que atualmente se verifica no Brasil (decréscimo de mais de um terço entre 1970 e 1980 e ainda mais acentuado desde então - Ramos e col. ${ }^{18}$ 1987), não se traduz necessariamente em imediato envelhecimento da população em termos relativos. Ainda que a vida média do brasileiro tenha aumentado muito nesse final de século, as altas taxas de fertilidade do passado próximo ainda se refletirão nas pirâmides populacionais das próximas décadas. Isso se deve ao efeito tardio do alto número de nascimentos há 40,30 ou 20 anos - uma população jovem numerosa, que sobreviveu até a idade reprodutiva. Mesmo que eles tenham poucos filhos, o efeito multiplicador ainda é manifestado por algum tempo ${ }^{25}$ (Figura 4).

Como a taxa de fertilidade nos anos 60 era consideravelmente maior do que a atual, a base da pirâmide populacional de hoje é menor do que a de algumas décadas passadas, o que significa que a proporção de crian-

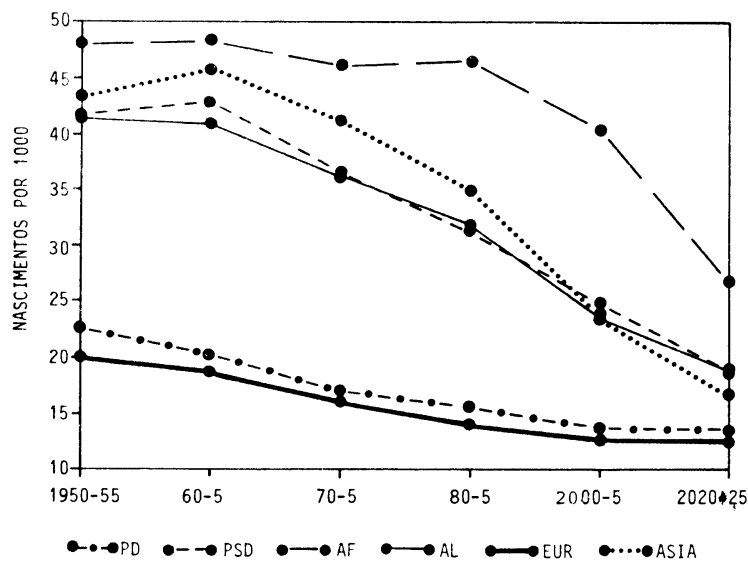

Fig. 3 - Taxas brutas de nascimento em algumas regiões do mundo - 1950-5/2020-5.

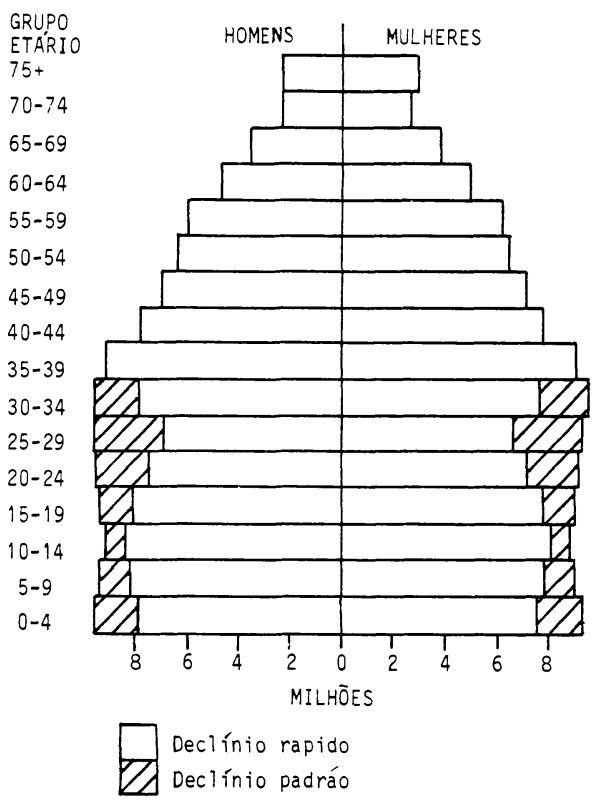

Fig. 4 - Pirâmides etárias do Brasil no ano 2000, assumindo declínios de fertilidade padrão e rápido. Fonte: World Development Report ${ }^{25}$ (1984)

ças está decrescendo e, conseqüentemente, a faixa adulta aumentando. Esta coorte nascida na década de 60 será, no ano 2020, a responsável pela pressão no topo da pirâmide populacional, fazendo-a ficar com um contorno mais retangular, caso seja mantida a tendência de baixo índice de fecundidade. $\mathrm{Na}$ Alemanha Ocidental, por exemplo, as taxas atuais de crescimento natural são negativas, ou seja, o número de nascimento é menor do que o de mortes. Isso faz com que hoje sua pirâmide populacional mostre uma base bem pequena em relação a décadas passadas e, portanto, uma grande proporção da população nos demais segmentos da pirâmide. As conseqüências socioeconômicas de tais modificações na estrutura etária de uma sociedade manifestamse por um longo tempo e são discutidas em outro artigo (Veras e col. ${ }^{22}$, 1987).

As estimativas de mudanças nas proporções de idosos refletem primariamente taxas de fecundidade no pas-

TABELA 7

Taxas brutas de nascimento (número de nascimentos por 1000 pessoas) nas diversas regiões do mundo entre $1950 / 5,1960 / 5,1970 / 5,1980 / 5,2000 / 5$ e $2020 / 5$

\begin{tabular}{lcccccc}
\hline \multicolumn{1}{c}{ Países } & $1950 / 5$ & $1960 / 5$ & $1970 / 5$ & $1980 / 5$ & $2000 / 5$ & $2020 / 5$ \\
\hline $\begin{array}{l}\text { Países } \\
\text { desenvolvidos }\end{array}$ & 22,7 & 20,3 & 17,0 & 15,5 & 13,8 & 13,5 \\
$\begin{array}{l}\text { Países } \\
\text { subdesenvolvidos }\end{array}$ & 41,8 & 42,8 & 36,4 & 31,2 & 24,8 & 18,5 \\
África & 48,1 & 48,3 & 46,1 & 46,4 & 40,4 & 26,7 \\
América & 41,4 & 41,0 & 36,3 & 31,8 & 23,7 & 18,8 \\
Latina & 19,8 & 18,7 & 16,1 & 16,0 & 12,6 & 12,6 \\
Europa & 43,2 & 45,8 & 41,1 & 34,9 & 23,3 & 16,6 \\
Ásia do Sul & & &
\end{tabular}

Fonte: United Nations ${ }^{17}, 1984$ 
sado e, ao mesmo tempo, hipóteses quanto às taxas reprodutivas brutas no futuro. A curto prazo, os decréscimos projetados nas taxas reprodutivas na maioria dos países irão reduzir a proporção de jovens e aumentar a de idosos. Se além disso ocorrer um decréscimo nas taxas de mortalidade de pessoas adultas e idosas, a proporção das mesmas em relação à população como um todo irá naturalmente aumentar ainda mais. Esse processo dinâmico no comportamento populacional tem sido chamado de transição epidemiológica por alguns ou demográfica por outros. Seus estágios são graduais e podem naturalmente demorar mais ou menos tempo, em resposta a um grande número de fatores inter-relacionados, conforme observa-se a seguir.

\section{TRANSIÇÃO EPIDEMIOLÓGICA, ESTÁGIOS}

1. Mortalidade concentrada nos primeiros anos de vida (grande percentagem da população é jovem)

2 . Mortalidade decresce; taxas de crescimento aumentam ou se mantêm elevadas (percentagem de jovens na população aumenta)

3 . Taxas de fertilidade decrescem; mortalidade continua a cair (aumento da percentagem de adultos jovens, e progressivamente de pessoas idosas)

4 . Mortalidade em todos os grupos etários continua a cair (aumento contínuo na percentagem de idosos na população)

Em última análise, o processo de transição epidemiológica descreve a gradual mudança de situações caracterizadas por alta-mortalidade/alta-fecundidade para a de baixa-mortalidade/baixa-fecundidade e, conseqüentemente, de uma baixa para uma alta proporção de idosos na população. Se o processo de transição epidemiológica é comprimido, isto é, se seus vários estágios se passam em um número menor de anos, as repercussões sociais serão muito mais acentuadas, particularmente se os recursos materiais da sociedade são limitados. Em grande parte, o maior problema é como absorver e lidar com as necessidades dos idosos quando as prioridades estão claramente relacionadas a outros grupos etários da população. Quanto maior o número de pessoas que envelhece, maior a necessidade de recursos para atender a suas necessidades específicas.

\section{AS MUDANÇAS NAS CAUSAS DE MORTALIDADE E MORBIDADE}

Em termos de saúde, o aumento do número de idosos em uma população se traduz em um maior número de problemas de longa duração, que com freqüência dependem de intervenções custosas envolvendo tecnologia complexa, para um cuidado adequado. Gradualmente se estabelece uma competição por recursos: de um lado problemas prementes, com alta mortalidade infantil ou desnutrição, de outro um número crescente de diabéticos, acidentes vasculares cerebrais ou demência senil.

A situação do Brasil, analisada por Imhof ${ }^{11}$ (1985) e ilustrada na Figura 5, mostra claramente essas transições. Em 1930, quase a metade das mortes ocorridas foi causada por doenças infecciosas e parasitárias. Em 1980, tais doenças foram responsáveis por pouco mais que $10 \%$ das mortes, praticamente a mesma percentagem de mortes causadas por doenças respiratórias ou por cân-

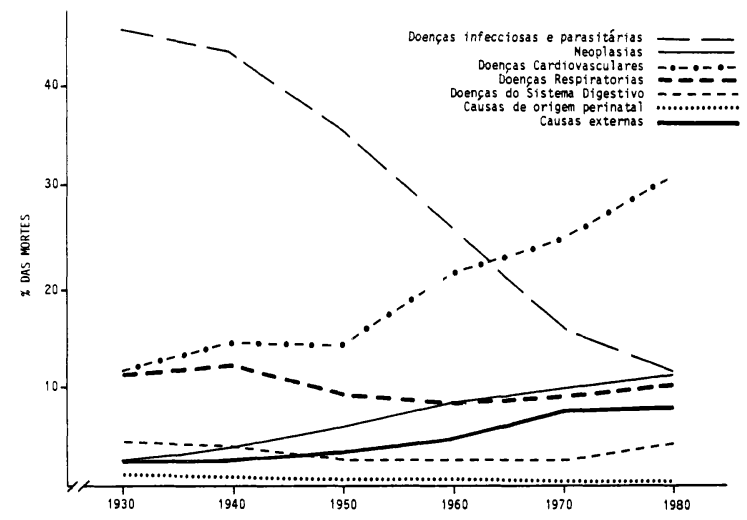

Fig. 5 - Evolução das causas de morte nas capitais brasileiras entre 1930 e 1980 (em percentagens) Fonte: RADIS: Dados ${ }^{15}$ (1983)

cer. O grupo integrado por doenças cardiovasculares passou a primeiro lugar, tendo sido responsável por um terço das mortes no Brasil em $1980^{15}$. As diferenças regionais são grandes - por exemplo, no Rio de Janeiro metade das mortes é causada por doenças cardiovasculares, enquanto que em Fortaleza, por exemplo, a proporção diminui para menos de um quarto das mortes ocorridas naquela capital (Ramos e col. ${ }^{18}, 1987$ ).

Portanto, ao lado de doenças infecciosas e parasitárias (que continuam sendo causas de mortes relativamente freqüentes quando o Brasil é comparado com outros países), as doenças crônicas, comuns das idades mais avançadas, estão se tornando progressivamente mais prevalentes num país como o nosso. A escassez de dados de morbidade dificulta comparações, mas certamente o contraste é ainda mais pronunciado.

A resposta a situações como essa é, em geral, inadequada. Em vez de um planejamento cuidadoso e a longo prazo, a tendência é de resolver problema por problema, à medida que eles aparecem. Isso reflete em grande parte a própria natureza dos mecanismos de tomada de decisões na maioria dos países, assoberbados pela imensidão de problemas a serem enfrentados simultaneamente. Ao final temos, inevitavelmente, decisões e ações que não refletem prioridades pré estabelecidas.

No que diz respeito à saúde da parcela mais idosa da população, a complexidade é agravada pela natureza de tais problemas: doenças que não podem ser resolvidas do dia para noite, que absorvem grandes quantidades de recursos materiais e humanos e que, em última análise, continuarão existindo por um longo período. Em outras palavras, se nada for feito em termos de se cuidar de um paciente com um problema cardiovascular ou com artrite hoje, amanhã ou em algum momento, ele acabará sendo objeto de assistência médica. A partir de uma entrada no sistema de prestação de serviços, o uso dos mesmos pode ser extraordinariamente prolongado. Tais doenças, com freqüência, não são de desfecho rápido ou dramático. Não são como uma gastroenterite ou uma broncopneumonia nos primeiros anos de 
vida, em que a cura ou a morte é uma questão que, em geral, se define em poucos dias. Em termos práticos, muitas vezes é mais fácil ignorar problemas como estes, da infância (pois eles freqüentemente desaparecem da vista dos profissionais de saúde com a mesma rapidez com que haviam surgido), do que negar a existência dos problemas dos idosos que tendem a voltar dia após dia à porta do hospital: algo acaba tendo de ser feito.

O desafio assim gerado é consideravel. De um lado países como o Brasil continuarão a mostrar, através de seus indicadores de saúde, as marcas do subdesenvolvimento e das desigualdades sociais por algum tempo. Por outro lado, tais países passarão a apresentar aumento da incidência e prevalência das doenças crônicodegenerativas e demais problemas comuns na terceira idade.

Em termos sociais, é impossível (e errôneo) argumentar que diante de altas taxas de mortalidade infantil ou de freqüêntes casos de desnutrição, doenças como câncer, hipertensão ou diabetes devam ser consideradas prioridades (Kalache ${ }^{12}$, 1986).

O crescimento da população idosa leva inevitavelmente a um aumento dos recursos despendidos na área de saúde. Para ilustrar a importância desse grupo etário em relação aos recursos despendidos na área da saúde, o exemplo da Inglaterra pode ser citado: nesse país, a população acima de 65 anos (cerca de $17 \%$ do total) utiliza $60 \%$ do orçamento do Departamento Nacional de Saúde e Cuidados Sociais (Gray7, 1985); mais da metade dos leitos hospitalares é por eles ocupada (já que o tempo médio de permanência dos mais idosos é cerca de duas vezes maior do que o dos demais grupos etários). Para a população ainda mais idosa, com 75 anos ou mais, o custo do tratamento médico-hospitalar é sete vezes maior que o despendido com outras faixas etárias. Os gastos com cuidados na comunidade são igualmente muito superiores: ainda que a grande maioria dos idosos viva na comunidade (na Inglaterra, apenas $5 \%$ das pessoas acima de 65 anos vivem em instituições como lares de idosos ou hospitais de longa permanência), sua manutenção é extremamente onerosa. Neste particular há que se considerar não somente os gastos com cuidados primários de saúde (o médico de família e sua equipe) como também os cuidados sociais, como por exemplo fornecimento de refeições, auxílio para as atividades domésticas ou suplementos para fazer face às despesas de aquecimento doméstico. A exemplo de outros países mais desenvolvidos, a Inglaterra despende com os idosos cerca de três vezes mais que o dispêndio per capita com o resto da população. Torna-se portanto necessária uma política de saúde cuidadosamente planejada de modo que os recursos disponíveis sejam usados com máxima eficiência (Grimley-Evans ${ }^{9}, 1986$ ).

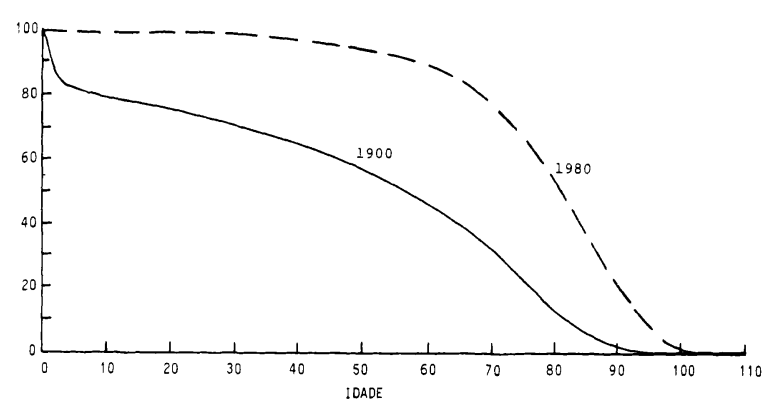

Fig. 6 - Curvas de mortalidade para a população feminima norte-americana em 1900 e em 1980 Fonte: $\mathrm{OMS}^{16}$ (1984)

\section{CURVAS DE MORTALIDADE, MORBIDADE E INCAPA- CIDADE}

Para se instruir os órgãos responsáveis pela saúde e cuidados sociais no que diz respeito ao planejamento de serviços e estimativa de demanda é necessário dispor de previsões sobre a mortalidade a ser experimentada por uma determinada população. Com freqüência, tais previsões são ilustradas através de um gráfico ou curva de mortalidade *.

Comparando-se por exemplo as curvas de mortalidade da população feminina dos Estados Unidos nascida em 1900 com a curva de 1980, as diferenças se tornam bem nítidas (Figura 6). No início do século a mortalidade infantil ainda era alta e, portanto, a população se vê sensivelmente diminuída ao atingir o primeiro ano de vida. Em comparação, em 1980, a mortalidade infantil era bem baixa e se verifica pouca perda no primeiro ano de vida. A partir daí as reduções são sempre mais acentuadas para a população nascida em 1900 e, progressivamente, a curva vai decaindo. A partir da idade adulta mais avançada, a curva começa a cair ainda mais acentuadamente até que a população original desaparece por completo. Isso se dá por volta do ano em que os nascidos completariam 85 anos de idade, ou seja, o limite biológico de vida para a espécie humana. Tal limite, como já foi visto anteriormente, não parece ter aumentado desde a antiguidade: tornar-se um centenário é um fato tão excepcional hoje quanto em qualquer ponto da História.

Da mesma forma como a construção de curvas de mortalidade depende do conhecimento do número de nascimentos e do número de mortes experimentado pela mesma população, a construção de curvas de morbidade é viável, desde que se conheça o número de pessoas acometidas por enfermidades crônicas na população em estudo. Uma curva de morbidade mostra qual é a percentagem da população livre de doenças crônicas. O mesmo princípio pode ser aplicado em relação a incapacidades funcionais irreversíveis, desde que tais episódios sejam também registrados para a população; uma alternativa é projetar dados a partir de inquéritos que investiguem especificamente a prevalência de inca-

\footnotetext{
* Tais curvas podem ser obtidas a partir de dados extraídos de tábuas de vida que são relativamente simples de serem construídas desde que se tenha o número total de nascidos em um determinado período (um ano, por exemplo) e o número de mortes ocorridas em tal população no decorrer do mesmo período. A curva de mortalidade mais comumente utilizada é construída colocando-se a percentagem da população que permanece viva (sobrevivência cumulativa) no eixo vertical e a idade (em anos) em que ocorre a morte no eixo horizontal.
} 
pacidades em uma comunidade. $\mathrm{O}$ conjunto das três curvas pode, portanto, mostrar o número total de sobreviventes em qualquer altura da vida de uma população, quantos destes sobreviventes estão livres de doenças (população sã) e finalmente quantos estão com suas capacidades funcionais intactas (Organización Mundial de la Salud, ${ }^{16} 1984$ - Figura 7).

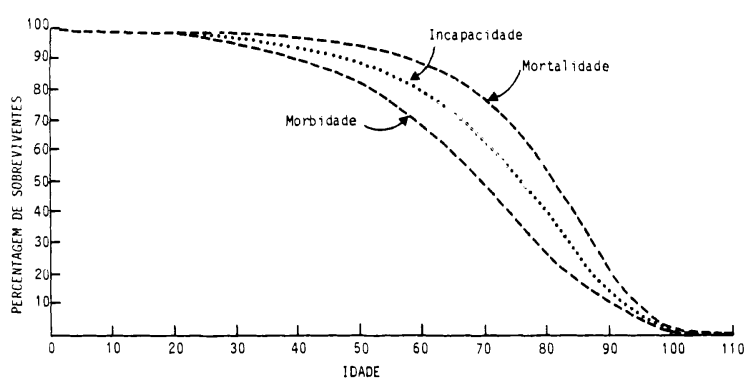

Fig. 7 - Curva de mortalidade para a população feminina norte-americana em 1980 e curvas hipotéticas de morbidade e incapacidade para a mesma população Fonte: OMS ${ }^{16}(1984)$

\section{A CURVA RETANGULAR}

Considerando que uma curva de sobrevivência expressa a percentagem da população que permanece viva num determinado momento, seu formato pode naturalmente variar de acordo com a mortalidade experimentada pela população em estudo (Fries $\left.{ }^{5}, 1980\right)$. Por exemplo, em um meio ambiente selvagem e hostil, os indivíduos estão expostos a riscos - tanto sob a forma de agressões como de doenças - que fazem com que a morte seja um evento plausível em qualquer período da vida. A curva de sobrevivência resultante tem portanto uma configuração exponencial em que perdas (mortes) ocorrem dia a dia em qualquer idade. Já para populações mais protegidas, vivendo em comunidades em que o meio ambiente está mais controlado, a morte passa a ser postergada até os limites biológicos da capacidade do homem de sobreviver. Gradualmente, a curva assume uma configuração retangular, ou seja, o número de perdas precoces é mínimo e os indivíduos tendem a morrer em idades próximas ao limite máximo possível para a espécie humana (Figura 8).

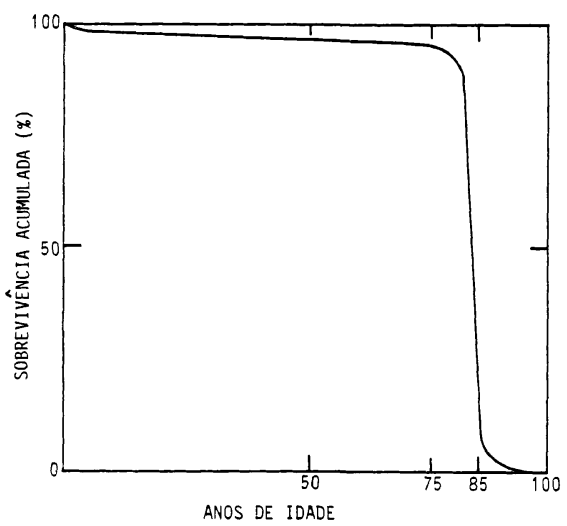

Fig. 8 - A curva de mortalidade (hipotética) Fonte: Fries e Crapo ${ }^{6}(1981)$
Atualmente, vários países industrializados estão se aproximando de tais curvas de contorno retangular. No entanto, as evidências de que as curvas de morbidade e de incapacidade também estejam se "regularizando" são ainda contraditórias. Ou seja, mesmo que progressivamente um número maior de pessoas morra em idades mais e mais avançadas, não há ainda nenhuma evidência inequívoca de que um número igualmente maior de pessoas esteja atingindo esse limite biológico de vida em pleno gozo de suas capacidades físicas e mentais. Alguns estudos que permitam elucidar essa questão estão ora em curso, mas são necessários muitos mais para uma conclusão definitiva (Svanborg ${ }^{21}, 1985$ ). As implicações para os serviços sociais e de saúde são imensas. Se em uma população os indivíduos atingirem idades cada vez mais avançadas mantendo boas condições de saúde e autonomia, não há maiores problemas para a sociedade em questão. Se, no entanto, essa sobrevivência mais longa for acompanhada por períodos de doenças prolongadas e conseqüente perda de autonomia, os recursos necessários para fazer face aos problemas gerados podem escalar até níveis impossíveis de serem absorvidos por tal sociedade.

\section{ENVELHECIMENTO CRONOLÓGICO VERSUS ENVELHECIMENTO FUNCIONAL: O CONCEITO DE AUTONOMIA}

O conceito de capacidade funcional é particularmente útil no contexto do envelhecimento. Envelhecer mantendo todas as funções não significa problema quer para o indivíduo ou para a comunidade; quando as funções começam deteriorar é que os problemas começam a surgir. $\mathrm{O}$ conceito está intimamente ligado à manutenção de autonomia que pode ser mais bem compreendido através de um exemplo; se um homem idoso que tenha sofrido um acidente vascular cerebral (deixando algumas seqüelas moderadas) se torna viúvo, sua vida passa naturalmente por uma verdadeira revolução. Suponhamos que tal homem viva só e não saiba cozinhar; sua situação o torna imediatamente dependente, a ponto de ter que se considerar sua transferência para uma ins tituição (lar de idosos) caso não seja possível mobilizar recursos comunitários que possam mantê-lo em sua própria moradia. Por exemplo, se ele passa a contar com a ajuda de alguém que venha à sua casa diariamente preparar sua comida, seu estado de dependência permanece inalterado, embora ele tenha recuperado sua autonomia. O mesmo se pode dizer de uma pessoa idosa com grau severo de artrite; chega-se a um ponto em que sua autonomia está severamente comprometida pois ela não pode mais, por exemplo, usar o banheiro que está no segundo andar da moradia. Se suas condições econômicas permitem a construção de um banheiro no primeiro piso, sua autonomia em permanecer vivendo na comunidade é imediatamente restabelecida.

Na velhice, a manutenção de autonomia está intimamente ligada à qualidade de vida. Portanto, uma forma de se procurar quantificar a qualidade de vida de um indivíduo é através do grau de autonomia com que o mesmo desempenha as funções do dia-a-dia que o fazem independente dentro de seu contexto socioeconômico-cultural (Grimley-Evans ${ }^{9}$, 1984). Sob o ponto de vista prático, há várias formas de se medir tais funções 
- fundamentalmente através do desempenho de atividades diárias (Fillenbaum $\left.{ }^{4}, 1984\right)$; por exemplo, a autonomia de um idoso que viva em uma grande cidade de um país desenvolvido pode ser medida através de sua capacidade de cuidar de si próprio (higiene pessoal, preparo de refeições, capacidade de fazer suas próprias compras, manutenção básica da casa, e outras). Já para um idoso que vive em uma zona rural de um país subdesenvolvido, autonomia pode significar algo muito mais complexo - por exemplo, capacidade de realizar trabalho físico pesado na lavoura. Nesse sentido, portanto, o conceito de envelhecimento cronológico passa a ser de relevância muito menor do que o conceito de envelhecimento funcional. As dificuldades em operacionalizar tal conceito são, naturalmente, inúmeras. No entanto, sob o ponto de vista de planejamento, a abordagem funcional é a mais importante e, conseqüentemente, uma área de crescente interesse para pesquisa (Kane e Kane ${ }^{14}$, 1981). Há ainda que se ressaltar que, em decorrência das precárias condições de vida nos países subdesenvolvidos, o envelhecimento funcional precede o cronológico e muitas vezes é bastante precoce. Um operário que passa 20 ou 30 anos trabalhando em condições ambientais adversas, desempenhando atividades físicas muito além de sua própria força, mal nutrido, sem condições adequadas de lazer, enfrentando todo o estresse de uma grande cidade do Terceiro Mundo, com condições de moradia inadequadas e submetendo-se a várias horas por semana a sistemas de transporte urbano totalmente impróprio, tal operário, ao chegar aos cinqüenta anos, já está funcionalmente envelhecido. $\mathrm{O}$ mesmo se pode dizer de uma mulher aos quarenta anos após dez, quinze gestações a termo, longos períodos de lactação sem estar bem alimentada, sem descanso na incessante tarefa de cuidar dos filhos, da casa e, muitas vezes com co-responsabilidades financeiras na família. Nos países do Terceiro Mundo, envelhecimento pode preceder em muito a barreira artificial dos sessenta ou sessenta e cinco anos.

\section{O ENVELHECIMENTO POPULACIONAL NO CONTEXTO DE PROFUNDAS MUDANÇAS SOCIAIS}

Com freqüência, outras profundas transformações ocorrem em uma sociedade simultaneamente a rápidas mudanças demográficas. Não só um processo de envelhecimento prematuro está ocorrendo em vários países menos desenvolvidos, como também tranformações culturais e sociais imensas estão em curso. O Brasil, por exemplo, é um país onde há 35 anos dois terços de uma população de 50 milhões de habitantes viviam em zonas rurais. Hoje em dia, praticamente três quartos dos 130 milhões vivem em áreas urbanas, metade dos quais em aglomerados urbanos de mais de um milhão de pes- soas. Urbanização, muitas vezes (mas não necessariamente) associada a industrialização, transforma radicalmente uma sociedade. Valores tradicionais são substituídos, a informação técnica torna-se mais valiosa que o conhecimento acumulado a ser transferido de uma geração para outra; a dinâmica familiar muda e gradualmente os elos da grande família são desfeitos, dando lugar a família nuclear de pais e (poucos) fillhos. Expectativas diante da vida das mulheres também mudam devido, por exemplo, a um crescente número de mulheres na força de trabalho remunerado. Com o crescimento da população idosa aumentam também os gastos estatais para a manutenção da parcela economicamente improdutiva. Em outras palavras, aumenta a relação de dependência entre a parcela economicamente ativa e a nãoprodutiva da população (Veras e col. ${ }^{22}$, 1987). O resultado prático desses e de outros fatores é claramente ilustrado em relação aos cuidados com a população idosa. A atenção tradicionalmente proporcionada pelas famílias vai sendo gradualmente substituída pela necessidade de uma intervenção crescente do Estado e/ou de outras formas de cuidado institucional. Deve-se ressaltar que os sistemas de seguro sociais são inadequados na maioria dos países menos desenvolvidos e tais alternativas são naturalmente muito mais onerosas e com freqüência também difíceis de serem aceitas pelos mais velhos.

O envelhecimento de sua população é uma aspiração natural de qualquer sociedade. Mas tal, por si só, não é bastante; é também importante almejar uma melhoria da qualidade de vida daqueles que já envelheceram ou que estão no processo de envelhecer. Manutenção de autonomia e independência é uma tarefa complexa que resulta dessa conquista social. $O$ desafio para os países subdesenvolvidos é considerável; no passado, quando as populações dos países européus começaram a envelhecer, tais países eram os mais ricos e poderosos do mundo. Tome-se a Inglaterra como exemplo; o envelhecimento de sua população teve início após a Revolução Industrial e no período áureo do Império Britânico. Portanto, a sociedade inglesa pode teoricamente dispor de recursos para fazer face às mudanças ditadas pela transformação demográfica que ainda está em curso naquele país. Hoje, quando vários dos países subdesenvolvidos vêem suas populações envelhecerem, a situação é distinta. Tais países não completaram ainda um ciclo econômico e político e permanecem carentes em vários sentidos; não dispõem de um império fornecendo riquezas e um mercado assegurado para seus produtos. $\mathrm{O}$ modo como os países subdesenvolvidos responderão a esse desafio proposto pelo envelhecimento de suas populações dependerá em grande parte do grau de sensibilização ao problema por parte da sociedade como um todo e de seus profissionais e políticos em particular. 
KALACHE, A. et. al. [The ageing of the world's population. A new challenge]. Rev. Saúde públ., S. Paulo 21:200-10, 1987

ABSTRACT: Ageing has now become a universal phenomenon, of increasing importance to developed and developing countries alike. In this, the first of a series of articles on ageing in developing countries, the actual demographic revolution is discussed, with special reference to Brazil. Estimates are provided up to the year 2025. The article analyses the factors which are responsible for this ageing process - such as the rapid decline in fertility and mortality rates that many Third Word countries have been experiencing over the last few years - and the various gradual stages of this process, which is usually referred to as the 'epidemiological transition', are discussed. The consequences for any society with a population that is gradually becoming older are considerable, and are of particular importance for the Health Sector. The article discusses the changing morbidity and mortality patterns and the concept of autonomy as a possible way to quantify quality of life is introduced. On this particular point a suggestion is made to redefine the concept of 'Ageing', in order to take into consideration the context in which senior adults in the Third World live. Finally, the article addresses itself to points relating to the interaction of ageing and social change. That there is such an interaction is apparent in developing countries and this raises questions to which answers could be found through the use of the epidemiological method.

UNITERMS: Demographic aging, trends. Mortality rate, trends. Fertility rate, trends. Life expectancy. Quality of life. Social change.

\section{REFERÊNCIAS BIBLIOGRÁFICAS}

1. ALDESTEIN, A. Tuberculosis death: a generation effect. Pop. Trends, 8:20-3, 1977.

2. ANUÁRIO ESTATÍSTICO DO BRASIL. (Fundação IBGE). Rio de Janeiro, 1982.

3. ANZOLA-PEREZ, E. Ageing in Latin American and the Caribbean. In: Pan-American Health Organization. Toward the well-being of the elderly. Washington, D.C., 1985.p.9-23. (PAHO - Publ. Scient., 492).

4. FILLENBAUM, G. The well-being of the elderly: approaches to multidimensional assessment. Geneva, World Health Organization, 1984. (Technical Report, 84).

5. FRIES, J.F. Aging, natural death and the compression of mortality. New Engl.J.Med., 303 : 130-5, 1980.

6. FRIES, J.F. \& CRAPO, L.M. Vitality and aging: implications of the retangular curve. San Francisco, W.H. Freeman \& Co., 1981.

7. GRAY, J.A.M. Social and community aspects of ageing. In: Pathy, M.S.J., ed. Principles and practice of geriatric medicine. Chichester, Wiley \& Sons, 1985.

8. GRIMLEY-EVANS, J. Prevention of age-associated loss of autonomy: epidemiological approches. J. chron. Dis., 37:353-63,1984.

9. GRIMLEY-EVANS, J. The health of an ageing population. In: Bitles, A.H. \& Collins, K.Y., ed. The biology of human ageing. Cambridge, University Press, 1986. p. 201-14.

10. HOOVER, S.L. \& SIEGEL, J.A. International demographic trends and perspectives on aging. J.Cross-Cult. Geront., 1:5-30, 1986.

11. IMHOF, A.E. Mortality problems in Brazil and in Germany: past-present-future: learning from each other? Rev. Saúde públ., S. Paulo, 19:233-50,1985.

12. KALACHE, A. Ageing in developing countries: meeting the challenge. Hlth Pol. Plan., 1:171-5,1986.

13. KALACHE, A. \& GRAY, J.A.M. Health problems of older people in the developing world. In: Pathy, M.S.J., ed. Principles and practice of geriatric medicine. Chichester, John Wiley \& Sons, 1985. p. 1279-87.
14. KANE, R.A. \& KANE, R.L. Assessing the elderly: a practical guide to measurement. Lexington, MA, Lexington Books, 1981.

15. MORTALIDADE nas capitais brasileiras 1930-1980. RADIS-Dados, (7):1-8,1984.

16. ORGANIZACION MUNDIAL DE LA SALUD. Grupo Científico sobre la Epidemiologia del Envejecimiento, Ginebra, 1983. Aplicaciones de la epidemiologia al estudio de los ancianos; informe. Ginebra, 1984. (Ser.Inf.técn., 706).

17. PERIODICAL ON AGEING 84. (United Nations). New York, 1(1) 1985.

18. RAMOS, L.R.; VERAS, R.P.; KALACHE A. Envelhecimento populacional: uma realidade brasileira. Rev. Saúde públ., S. Paulo, 21:211-24, 1987.

19. SACHER, G.A. Biological prospects for life extension. In: Danon, D.; Shock, N.W.; Marois, M., ed. Aging: a challenge to science and society: biology. Oxford, Oxford Medical Publications, 1981. v. 1, p. 159-79.

20. SIEGEL, S.J. \& HOOVER, L.Ṣ. Demographic aspects of the health of the elderly to the year 2000 and beyond. Wld Hlth Stat., 35:133-202, 1982.

21. SVANBORG, A.; LANDAHL, S.; MELLSTROM, D. Basic issues of health care. In: Thomae, H. \& Maddox, G.L., ed. New perspectives on old age: a message to decision makers. New York, Springer Publ., 1985. p. 31-52.

22. VERAS, R.P.; RAMOS, L.R.; KALACHE, A. Crescimento da população idosa no Brasil: transformações e conseqüências na sociedade. Rev. Saúde públ., S. Paulo, 21:225-33, 1987.

23. WORLD HEALTH STATISTICS ANNUAL. (World Health Organization). Geneva, 1979.

24. WORLD HEALTH STATISTICS ANNUAL. (World Health Organization). Geneva, 1982.

25. WORLD Development Report. New York, Oxford University Press, 1984.

Recebido para publicação em 21/10/1986

Aprovado para publicação em 12/02/1987 